\title{
Preparation of Well-Defined Polymer by Polymer-Coupling Reaction. IX. Grafting Reaction of a Living Polytetrahydrofuran with a Polymer Having Alkali Metal Phenolate as Pendants*
}

\author{
Ryuzo AsAmI, Mikio TAKAKI, Yoshinori HARIMA, \\ and Shigeyuki TSUZUKI \\ Department of Synthetic Chemistry, Nagoya Institute of Technology, \\ Gokiso-cho, Showa-ku, Nagoya 466, Japan.
}

(Received June 30, 1980)

\begin{abstract}
Living polytetrahydrofuran (PTHF) was grafted on a polymer having alkali metal phenolate as pendants $(\mathrm{P}(\mathrm{HS}-c o-\mathrm{S})-\mathrm{M}: \mathbf{P}(\mathrm{HS}-c o-\mathrm{S})=\operatorname{poly}(p$-hydroxystyrene-co-styrene $)$; $\mathrm{M}=\mathrm{Li}, \mathrm{Na}$, and $\mathrm{K}$ ) under various reaction conditions. The extent of grafting of the living PTHF was approximately $100 \%$ in a grafting reaction with $\mathrm{P}(\mathrm{HS}-\mathrm{co}-\mathrm{S})-\mathrm{Na}$ at $0^{\circ} \mathrm{C}$, but decreased to $78 \%$ at $30^{\circ} \mathrm{C}$. The effect of counter cations of pendant metal phenolate anions on the grafting reaction was observed and it was indicated that the grafting efficiency increased in the order of $\mathrm{K}^{+}<\mathrm{Li}^{+}<\mathrm{Na}^{+}$, whereas the grafted polymer produced was monodisperse in the order of $\mathrm{K}^{+}<\mathrm{Na}^{+}<\mathrm{Li}^{+}$. The more monodisperse graft polymer was obtained with an increase in the mole ratio of the living ends

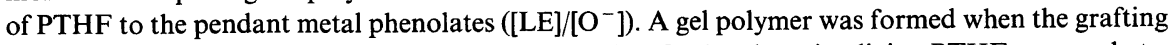
reaction was performed under the condition of $[\mathrm{LE}] /\left[\mathrm{O}^{-}\right]>1$ or by using living PTHF prepared at a conversion above $6.3 \mathrm{wt} \%$. The graft polymer could be isolated from the recovered polymer by extraction with isopropyl alcohol.
\end{abstract}

KEY WORDS Grafting Reaction / Polytetrahydrofuran / Poly $(p-$ hydroxystyrene-co-styrene) / Graft Copolymer / Molecular-Weight Distribution /

For the synthesis of a well-defined graft polymer by the coupling reaction of living polytetrahydrofuran (PTHF), it is interesting to find a backbone polymer having functional groups which couple with living PTHF at a high degree. Recently, Dreyfuss and Kennedy ${ }^{1}$ used a backbone polymer containing epoxide rings and Rempp et al. ${ }^{2}$ chose a polymer with dimethylanilino groups as pendants. In this paper, we are interested in using alakli-metalated poly ( $p$-hydroxystyrene- $c o$-styrene) (P(HS-co-S)) as multifunctional polymer, since Saegusa and Matsumoto ${ }^{3}$ have already demonstrated that sodium phenolate couples quantitatively with propagating species of living PTHF.

In the preceding paper, ${ }^{4}$ the alkali metalation of $\mathrm{P}(\mathrm{HS}-\mathrm{co}-\mathrm{S})$ was described with emphasis on the solubility of the resulting polymer, and in this paper,

* Part VIII: M. Takaki, R. Asami, and K. Kawabuchi, Nippon Kagaku Kaishi, 1555 (1979). the study of the grafting reaction of living PTHF with partially-metalated $\mathrm{P}(\mathrm{HS}-\mathrm{co}-\mathrm{S})$ is reported.

\section{EXPERIMENTAL}

\section{Materials}

The preparative method of $\mathrm{P}(\mathrm{HS}-\mathrm{co}-\mathrm{S})$ used is described in the preceding paper. ${ }^{4}$ The composition and the number-average molecular weight of the copolymer are $1 / 5.40(\mathrm{St} / p-\mathrm{HS} ; \mathrm{mol} / \mathrm{mol})$ and $1.27 \times 10^{5}$, respectively. The partially-metalated $\mathrm{P}(\mathrm{HS}-c o-\mathrm{S})$ (P(HS-co-S)-M) was obtained by the dropwise addition of an alkali naphthalene solution into a $\mathrm{P}(\mathrm{HS}-\mathrm{co}-\mathrm{S})$ solution with stirring. Triethyloxonium tetrafluoroborate $\left(\mathrm{Et}_{3} \mathrm{OBF}_{4}\right)$ was prepared according to Meerwein ${ }^{5}$ using a high vacuum system. The concentration of $\mathrm{Et}_{3} \mathrm{OBF}_{4}$ solution in 1,2-dichloroethane (EDC) was spectroscopically determined by measuring the concentration of phenyl ethyl ether $\left(\lambda_{\max }, 272 \mathrm{~nm} ; \varepsilon_{\max }\right.$, 
$1.93 \times 10^{3} 1 \mathrm{~mol}^{-1} \mathrm{~cm}^{-1}$ ) formed in the reaction with sodium phenolate. Tetrahydrofuran (THF, commerical reagent, EP grade) was purified by the usual method employed in anionic polymerization. EDC (commercial reagent, EP grade) was fractionally distilled under atmospheric pressure and then distilled from $\mathrm{CaH}_{2}$ in vacuo.

\section{Grafting Reaction}

The grafting reaction was carried out using the apparatus shown in Figure 1, except for the reaction in which the rate of the grafting was determined with the apparatus described in an earlier paper. ${ }^{6}$ The apparatus was evacuated on a high vacuum line (ca. $10^{-5} \mathrm{mmHg}$ ) and sealed off from the line; then, the $\mathrm{Et}_{3} \mathrm{OBF}_{4}$ solution in ampule I was introduced to reactor $B$ and the THF in ampule $T$ was transferred to reactor $\mathrm{B}$ so as to start the cationic polymerization of THF. While the polymerization of THF proceeded, the $\mathrm{P}(\mathrm{HS}-\mathrm{co}-\mathrm{S})-\mathrm{M}$ solution in ampule $\mathrm{P}$ was introduced into reactor $\mathrm{A}$. After a desired polymrization time, the living PTHF solution in reactor $\mathrm{B}$ was added dropwise to the $\mathrm{P}(\mathrm{HS}-\mathrm{co}-\mathrm{S})-\mathrm{M}$ solution with stirring by stirrer $\mathrm{S}$ for $2-3 \mathrm{~min}$. The grafting reaction was stopped by pouring the reaction mixture into a large amount of methanolwater $(3: 1, \mathrm{v} / \mathrm{v})$ at $0^{\circ} \mathrm{C}$. The precipitated polymer was filtered and dried in vacuo. The polymer thus obtained was dissolved again in benzene and freezedried.

\section{Gel-Permeation Chromatography Measurement and} the Determination of the Extent of Grafting

Gel-permeation chromatograms were measured on a Toyo Soda HLC-802UR with two GMH columns $(2 \mathrm{ft} \times 2$, Toyo Soda). THF was used as the eluant and the flow rate was $1 \mathrm{ml} \mathrm{min} \mathrm{m}^{-1}$. The polymer concentrations were less than $0.6 \mathrm{wt} \%$.

The extent of grafting of living PTHF was determined as follows. One $\mathrm{ml}$ of a grafting-reaction mixture was diluted with $5 \mathrm{ml}$ of THF for eluant and submitted to gel-permeation chromatography (GPC) measurement. The GPC curves were obtained simultaneously by using both ultraviolet (UV) and refractive index (RI) detectors. The former is sensitive to both ungrafted and grafted poly( $p$-hydroxystyrene-co-styrene)s, while the latter is sensitive to homo PTHF, $\mathrm{P}(\mathrm{HS}-c o-\mathrm{S})$, and graft polymer. On the curve, the peaks ascribed to graft polymer and uncoupled PTHF were distinguishable

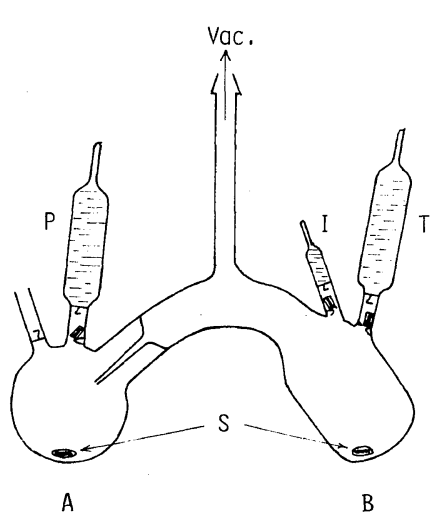

Figure 1. Apparatus for the polymerization of THF and grafting reaction. Symbols are shown in the text.

from each other in most cases. Accordingly, if the ratio of the sensitivities of $\mathrm{P}$ (HS-co-S) to the two detectors is known, a GPC curve by the RI detector can be divided into three areas, i.e., those of P(HSco-S) moiety, grafted PTHF, and ungrafted PTHF. The extent of grafting of living PTHF, i.e., grafted PTHF/(grafted PTHF + ungrafted PTHF), was determined by means of weighing papers cut out along the curves of grafted and ungrafted PTHF.

\section{Calculation of the Number of Branches}

The number of branches per backbone polymer molecule $(N)$ was estimated by two methods. One is based on the change in the number-average molecular weight of $\mathrm{P}(\mathrm{HS}-\mathrm{co}-\mathrm{S})$, viz.,

$$
N=\frac{\left(M_{n}\right)_{\mathrm{g}}-\left(M_{n}\right)_{\mathrm{bac}}}{\left(M_{n}\right)_{\mathrm{br}}}
$$

where $\left(M_{n}\right)_{\mathrm{g}},\left(M_{n}\right)_{\mathrm{bac}}$, and $\left(M_{n}\right)_{\mathrm{br}}$ are the numberaverage molecular weights of graft polymer, $\mathrm{P}(\mathrm{HS}$ $c o-\mathrm{S})$, and branches, respectively. The numberaverage molecular weights were estimated from GPC curves by using calibration curves of standard polystyrene samples which are commercially available and PTHF samples which were prepared by the polymerization of THF with $\mathrm{Et}_{3} \mathrm{OBF}_{4} .\left(M_{n}\right)_{\mathrm{bac}}$, however, was determined by the osmotic-pressure measurement in toluene at $37^{\circ} \mathrm{C}$, using a Knauer membrane osmometer. The other method is based on the extent of grafting of living PTHF, viz.,

$$
N=\left(n_{\mathrm{OM}}\right)\left([\mathrm{I}] /\left[\mathrm{O}^{-}\right]\right)([\mathrm{LE}] /[\mathrm{I}])(\mathrm{EG})
$$

where $n_{\mathrm{OM}},[\mathrm{I}] /\left[\mathrm{O}^{-}\right],[\mathrm{LE}] /[\mathrm{I}]$, and $\mathrm{EG}$ are the 


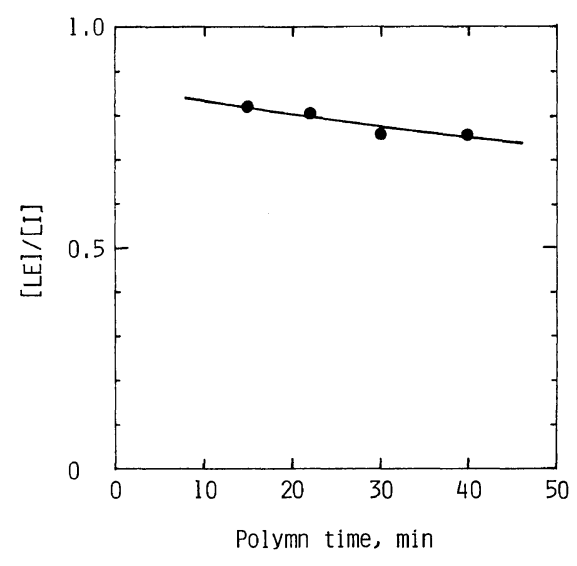

Figure 2. Variation in the amount of living ends of PTHF per initiator $\left(\mathrm{Et}_{3} \mathrm{OBF}_{4}\right)$ with polymerization time; $[\mathrm{THF}]_{0}, 11.8 \mathrm{moll}^{-1}$.

number of pendant metal phenolates per $\mathrm{P}(\mathrm{HS}-\mathrm{co}$ $\mathrm{S})$-M, the mole ratio of $\mathrm{Et}_{3} \mathrm{OBF}_{4}$ as initiator of the THF polymerization to pendant metal phenolates, the mole ratio of living ends of PTHF (LE) to the initiator, and the extent of grafting of living PTHF, respectively. The mole ratio of $[\mathrm{LE}] /[\mathrm{I}]$ was evaluated from the plot of $[\mathrm{LE}] /[\mathrm{I}] v s$. polymerization time (Figure 2) since it was shown ${ }^{7}$ that the amount of living ends of PTHF is quantitatively estimated by the "Phenoxyl End-Capping" method; the amount of the phenoxyl end-capped PTHF was determined using the UV detector of GPC.

\section{RESULTS AND DISCUSSION}

\section{Grafting Reaction}

Although no living PTHF at all was grafted on $\mathrm{P}(\mathrm{HS}-\mathrm{co}-\mathrm{S})$, the grafting reaction of living PTHF with $\mathrm{P}(\mathrm{HS}-\mathrm{co}-\mathrm{S})-\mathrm{Na}$ proceeded very rapidly, quantitatively, and homogeneously under suitable reaction conditions. That is, the grafting reaction with $\mathrm{P}$ (HS-co-S)-Na completed within $5 \mathrm{~min}$ even at $0^{\circ} \mathrm{C}$ and the extent of grafting of living PTHF was approximately $100 \%$ at $0^{\circ} \mathrm{C}$ as demonstrated in Figure 3. Also, Table I shows that living PTHF is quantitatively grafted on $\mathrm{P}(\mathrm{HS}-\mathrm{co}-\mathrm{S})-\mathrm{Na}$ at $0^{\circ} \mathrm{C}$ over the range of $[\mathrm{I}] /\left[\mathrm{O}^{-}\right]$ratio from 0.26 to 0.94 . The extent of grafting, however, decreased with an increase in reaction temperature; e.g., it decreased to $78 \%$ at $30^{\circ} \mathrm{C}$ as shown in Table $\mathrm{I}$.

The grafting reactions with $\mathrm{P}(\mathrm{HS}-c o-\mathrm{S})-\mathrm{M}$

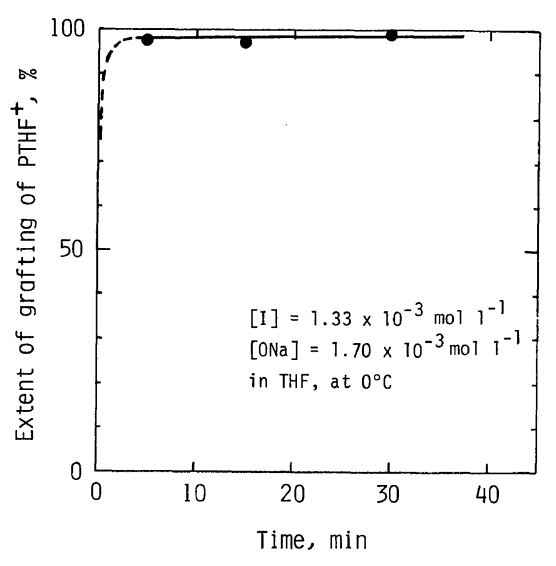

Figure 3. Time course of the extent of grafting of living $\mathrm{PTHF}$ in the grafting reaction with $\mathrm{P}(\mathrm{HS}-\mathrm{co}-\mathrm{S})-\mathrm{Na}$.

$(\mathrm{M}=\mathrm{Li}, \mathrm{Na}$, and $\mathrm{K})$ were carried out at room temperature and various ratios of $[\mathrm{I}] /\left[\mathrm{O}^{-}\right]$and the results are shown in Table II. As the $[\mathrm{I}] /\left[\mathrm{O}^{-}\right]$ratio increased, the extent of grafting decreased in the presence of any counter cations of pendant metal phenolate anions. The effect of the counter cation on the degree of grafting is remarkable at a high ratio of $[\mathrm{I}] /\left[\mathrm{O}^{-}\right]$, and in general it can be said that $\mathrm{Na}^{+}$is most favorable for obtaining a high degree of grafting. Figure 4 shows the GPC curves obtained by the UV detector, for the polymers recovered after the grafting reactions in Exptl no. L$1, \mathrm{~N}-1$, and $\mathrm{K}-1$. These curves show the change in the molecular-weight distribution of only backbone polymer since the UV detector is quite insensitive to PTHF moiety. In the case of P(HS-co-S)-Li, living PTHF is found to be grafted equally on all of the $\mathrm{P}$ (HS-co-S)-Li molecules but unequally in the case of $\mathrm{P}(\mathrm{HS}-\mathrm{co}-\mathrm{S})-\mathrm{K}$ and $-\mathrm{Na}$. In particular, in the case of $\mathrm{P}(\mathrm{HS}-\mathrm{co}-\mathrm{S})-\mathrm{K}$, three peaks appeared in the GPC curve. The peak at $V_{\mathrm{e}} \approx 30$ counts is unequivocally one of the ungrafted $\mathrm{P}(\mathrm{HS}-\mathrm{co}-\mathrm{S})$ and the others may be $\mathrm{P}(\mathrm{HS}-\mathrm{co}-\mathrm{S})$ grafted with PTHF. The reason why the peak of the graft polymer was divided into the peaks is not easy to explain at present. Anyway, the order of $\mathrm{K}^{+}<\mathrm{Na}^{+} \ll \mathrm{Li}^{+}$in the monodispersity of graft polymers was found to be the reverse order in the ionic strength of the $\mathrm{O}-\mathrm{M}$ bond. These results suggest that the reaction of living PTHF with P(HS$c o-\mathrm{S})-\mathrm{K}$ or $-\mathrm{Na}$ proceeds much more rapidly than with $\mathrm{P}(\mathrm{HS}-c o-\mathrm{S})-\mathrm{Li}$. 
R. Asami, M. TaKaKI, Y. Harima, and S. TsuzUKI

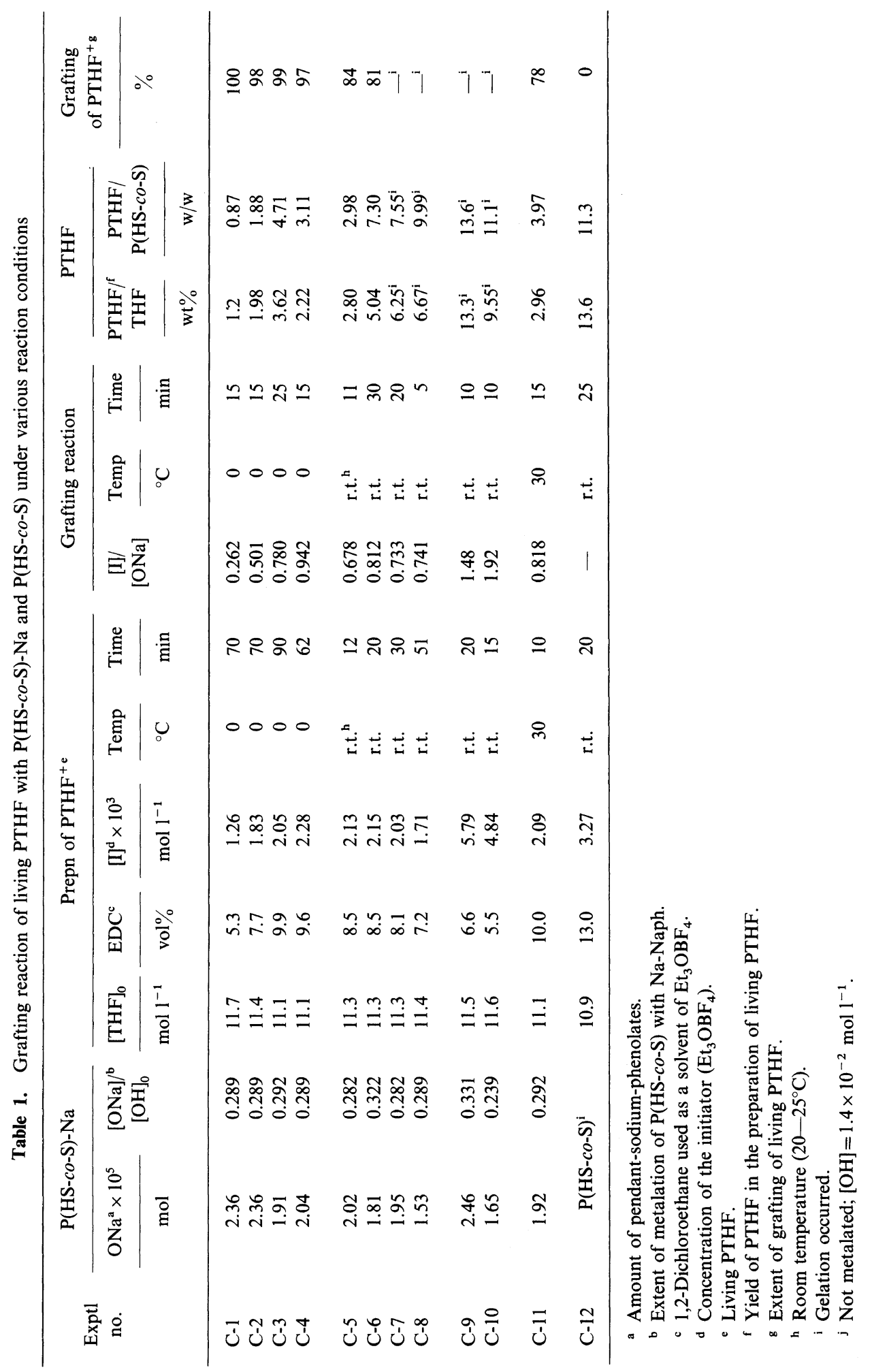


Table II. Effects of counter cations and $[\mathrm{I}] /\left[\mathrm{O}^{-}\right]$ratios on the extent of grafting of living $\mathrm{PTHF}^{\mathrm{a}}$

\begin{tabular}{|c|c|c|c|c|c|c|c|c|c|}
\hline \multirow{4}{*}{$\begin{array}{l}\text { Exptl } \\
\text { no. }\end{array}$} & \multicolumn{2}{|c|}{$\mathrm{P}(\mathrm{HS}-c o-\mathrm{S})-\mathrm{M}$} & \multicolumn{2}{|c|}{$\begin{array}{l}\text { Prepn of } \\
\text { PTHF }^{+c}\end{array}$} & \multicolumn{2}{|c|}{ Grafting reaction } & \multicolumn{2}{|c|}{ PTHF } & \multirow{4}{*}{$\begin{array}{c}\begin{array}{c}\text { Grafting } \\
\text { of } \text { PTHF }^{+}\end{array} \\
\%\end{array}$} \\
\hline & $\mathrm{OM}^{\mathrm{b}} \times 10^{5}$ & {$[\mathrm{OM}] /[\mathrm{OH}]_{0}$} & {$[\mathrm{I}] \times 10^{3}$} & Time & {$[\mathrm{I}] /[\mathrm{OM}]$} & Time & PTHF/ & PTHF/ & \\
\hline & \multirow{2}{*}{$\mathrm{mol}$} & & & & & & THF & $\mathrm{P}(\mathrm{HS}-c o-\mathrm{S})$ & \\
\hline & & & $\mathrm{mol} \mathrm{I}^{-1}$ & $\min$ & & $\min$ & & $w / w$ & \\
\hline \multicolumn{10}{|c|}{$\mathrm{P}(\mathrm{HS}-c o-\mathrm{S})-\mathrm{Li}$} \\
\hline L-1 & 2.66 & 0.292 & 1.27 & 20 & 0.201 & 13 & 2.86 & 1.58 & 87 \\
\hline L-2 & 1.90 & 0.292 & 1.27 & 20 & 0.499 & 14 & 3.09 & 4.48 & 78 \\
\hline$L-3$ & 1.11 & 0.292 & 1.27 & 20 & 0.955 & 15 & 2.80 & 7.22 & 72 \\
\hline \multicolumn{10}{|c|}{$\mathrm{P}(\mathrm{HS}-c o-\mathrm{S})-\mathrm{Na}$} \\
\hline $\mathrm{N}-1$ & 3.27 & 0.289 & 2.68 & 15 & 0.197 & 14 & 4.20 & 1.14 & 86 \\
\hline $\mathrm{N}-2$ & 2.02 & 0.282 & 2.13 & 12 & 0.678 & 11 & 2.80 & 1.98 & 84 \\
\hline $\mathrm{N}-3$ & 1.68 & 0.289 & 2.68 & 15 & 0.940 & 15 & 4.39 & 5.82 & 82 \\
\hline \multicolumn{10}{|c|}{$\mathrm{P}(\mathrm{HS}-c o-\mathrm{S})-\mathrm{K}$} \\
\hline $\mathrm{K}-1$ & 2.77 & 0.299 & 1.22 & 20 & 0.200 & 11 & 2.68 & 1.69 & 80 \\
\hline $\mathrm{K}-2$ & 1.93 & 0.299 & 1.22 & 20 & 0.499 & 10 & 3.07 & 4.93 & 66 \\
\hline $\mathrm{K}-3$ & 1.15 & 0.299 & 1.22 & 20 & 0.948 & 12 & 2.65 & 7.77 & 67 \\
\hline
\end{tabular}

a Polymerization of THF and the grafting reaction were done at room temperature.

b Amount of pendant metal phenolates.

c Initial concentration of THF was $11.3 \pm 0.3 \mathrm{~mol}^{-1}$. Other explanatory notes are the same as in Table $\mathrm{I}$.

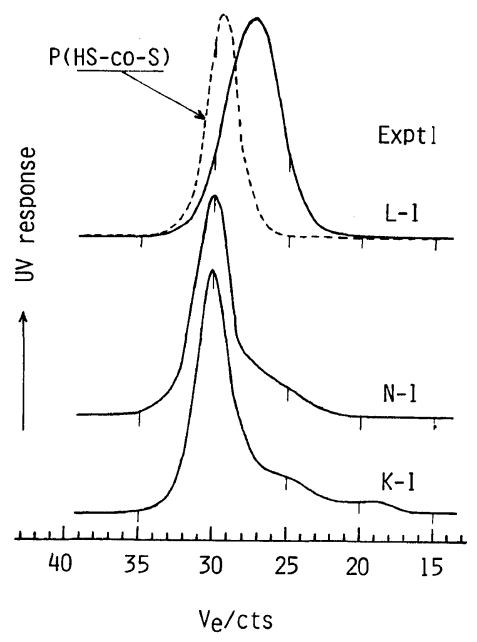

Figure 4. GPC traces of P(HS-co-S) (---) and polymers obtained in the grafting reactions with $\mathrm{P}(\mathrm{HS}-\mathrm{co}-\mathrm{S})-\mathrm{Li}$ (Exptl no. L-1), P(HS-co-S)-Na (Exptl no. $\mathrm{N}-1$ ), and $\mathrm{P}(\mathrm{HS}-c o-\mathrm{S})-\mathrm{K}($ Exptl no. $\mathrm{K}-1)$ at $[\mathrm{I}] /\left[\mathrm{O}^{-}\right] \fallingdotseq 0.2$.

\section{Side Reactions}

As can be seen from the above results, the grafting reaction of living PTHF with $\mathrm{P}(\mathrm{HS}-c o-\mathrm{S})-\mathrm{M}$ involved side reactions to some extent, except for the grafting reaction with $\mathrm{P}(\mathrm{HS}-\mathrm{co}-\mathrm{S})-\mathrm{Na}$ at $0^{\circ} \mathrm{C}$. One of these side reactions produced homo PTHF, whose molecular weight was in good agreement with the molecular weight estimated from the conversion of the polymerization of THF. Considering this fact and the effects of the reaction conditions on the extent of grafting, we speculate that the side reaction which forms homo PTHF might be the abstraction of a $\beta$-hydrogen atom from a living end of PTHF by an oxide anion, and this $\beta$-elimination probably takes place in competition with the coupling reaction, being affected by reaction conditions.

Another side reaction which was observed as gelation occurred under the reaction conditions given in Table I. That is, the gel polymer which was insoluble in any solvent was formed, when THF was polymerized to a conversion above $6.3 \mathrm{wt} \%$ for a polymerization time longer than $30 \mathrm{~min}$ (Exptl no. C7 and C-8 in Table I). This finding suggests that the chain transfer of living PTHF to an ether group in PTHF took place at an even early stage of the bulk polymerization of THF and this chain transfer involved branched PTHF having an tertiary oxonium ion (I) and then the PTHF was endowed with 
two active sites at both ends (II) according to the following scheme. The species such as (II) would act as cross-linking reagents to $\mathrm{P}(\mathrm{HS}-c o-\mathrm{S})-\mathrm{M}$ Fujimoto et $a l .{ }^{8}$ reported that when the polymeri-

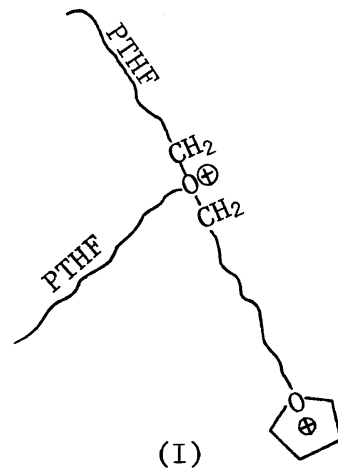

(I)

zation of THF was stopped at a conversion below $8 \%$, the chain transfer was negligible for the preparation of monodisperse PTHF. However, it is probable in the grafting reaction that the chain transfer is not negligible at a conversion of $6.3 \mathrm{wt} \%$ (Exptl no. C-7) and even a minute amount of the species is effective in forming the gel polymer.

In addition, gelation occurred in the course of the grafting reaction in the case of a mole ratio of $[\mathrm{LE}] /\left[\mathrm{O}^{-}\right]$greater than unity (Exptl no. C-9 and C10 in Table I). This gelation might be due to the excess of oxonium ions of living PTHF, and the following mechanism is suggested, Franta et al. ${ }^{9}$ have already proposed the mechanism of gelation similar to that described above in the cationic grafting polymerization of THF.

\section{Characterization of Graft Polymers}

The number of branches of the representative graft polymers was calculated by each of the two methods deacribed in the experimental section and are compared in Table III. In all cases, the number of branches calculated by use of the number-average molecular weight (eq 1) is somewhat smaller than that estimated on the basis of the extent of grafting of living PTHF (eq 2). This disagreement may be
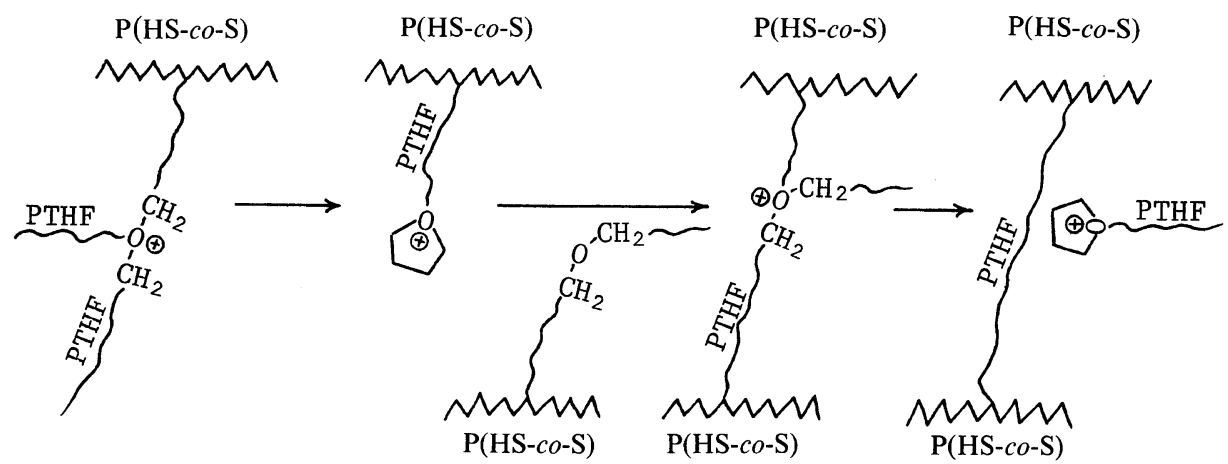

ascribed to the underestimation of the molecular weights of the graft polymers by GPC, because Kato et al. ${ }^{10}$ reported the elution counts of multibranched polymer to be somewhat larger than those of a linear polymer with the same molecular weight as the multibranched polymer.

Figure 5 shows the change in the molecular-

weight distribution of the backbone polymers in the grafting reactions carried out at various ratios of $[\mathrm{I}] /\left[\mathrm{O}^{-}\right]$. It can be seen that in the case of a low ratio of $[\mathrm{I}] /\left[\mathrm{O}^{-}\right](=0.197)$ a large amount of $\mathrm{P}(\mathrm{HS}-c o-\mathrm{S})$ remains ungrafted, but in a high ratio of $[\mathrm{I}] /\left[\mathrm{O}^{-}\right]$ (=0.94) ungrafted $\mathrm{P}(\mathrm{HS}-\mathrm{co}-\mathrm{S})$ is of a trace amount.

Even though the graft polymer recovered after the 
Table III. The number of branches of representative graft polymers

\begin{tabular}{|c|c|c|c|c|}
\hline \multirow{3}{*}{ Sample } & \multirow{3}{*}{$\begin{array}{l}\left(M_{n}\right)_{\mathrm{g}}^{\mathrm{b}} \\
\times 10^{-4}\end{array}$} & \multicolumn{3}{|c|}{ Branches } \\
\hline & & \multirow{2}{*}{$\begin{array}{l}\left(M_{n}\right)_{\mathrm{br}}^{\mathrm{c}} \\
\quad \times 10^{-4}\end{array}$} & \multicolumn{2}{|c|}{ No. of branches } \\
\hline & & & eq 1 & eq 2 \\
\hline L-3 & 91 & $2.8^{\mathrm{e}}$ & 28 & 30 \\
\hline $\mathrm{N}-2$ & 56 & $1.6^{\mathrm{e}}$ & 27 & 33 \\
\hline $\mathrm{C}-2$ & 23 & $1.0^{\mathrm{f}}$ & 10 & 11 \\
\hline $\mathrm{C}-3$ & 31 & $1.1^{\mathrm{f}}$ & 17 & 21 \\
\hline C-6 & 47 & $0.98^{\mathrm{e}}$ & 35 & 40 \\
\hline
\end{tabular}

a Sample number is identical with the experimental number in Tables I and II.

b $M_{n}$ of the graft polymer; based on GPC.

c $M_{n}$ of branches.

${ }^{d}$ Number of branches per P(HS-co-S) molecule was estimated from eq 1 and 2 in the experimental section.

e Based on GPC counts of uncoupled PTHF.

f Calculated from the PTHF yield and the value of $[\mathrm{LE}] /[\mathrm{I}]$.

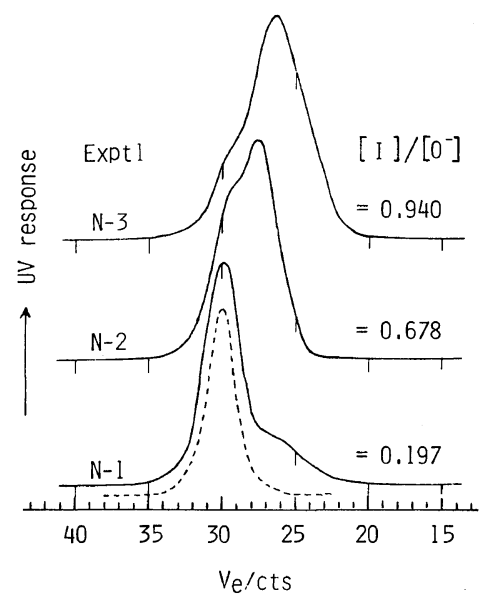

Figure 5. Molecular-weight distributions of P(HS-coS) (---) and polymers recovered after the grafting reactions with $\mathrm{P}(\mathrm{HS}-\mathrm{co}-\mathrm{S})-\mathrm{Na}$ at various ratios of $[\mathrm{I}] /\left[\mathrm{O}^{-}\right]$. grafting reaction was contaminated by ungrafted $\mathrm{P}\left(\mathrm{HS}-\mathrm{co}^{-\mathrm{S}}\right)$ and/or homo PTHF, the graft polymer was easily isolated from these homo polymers by simple procedures as follows. The polymer recovered after the grafting reaction (Exptl no. C-6) was extracted with hot $\left(80^{\circ} \mathrm{C}\right)$ isopropyl alcohol; the insoluble polymer (ungrafted $\mathrm{P}(\mathrm{HS}-c o-\mathrm{S})$ ) was separated by decantation; then, when the hot isopropyl alcohol solution of homo PTHF and graft polymer was slowly cooled to room temperature with stirring, the graft polymer was precipitated gradually. The precipitated graft polymer was filtered, washed with the alcohol, and dried in vacuo. The graft polymer thus obtained contains no homo polymer.

In conclusion, it may be noted that for the preparation of well-defined graft polymers, the grafting reaction with $\mathrm{P}(\mathrm{HS}-c o-\mathrm{S})-\mathrm{Na}$ should be carried out at $0^{\circ} \mathrm{C}$ and $[\mathrm{LE}] /\left[\mathrm{O}^{-}\right]=1$, by using living PTHF prepared at a conversion below $6.3 \mathrm{wt} \%$, and the control of the number of branches per P(HS-co$\mathrm{S})$ molecule should be made by adjusting the degree of the metalation of $\mathrm{P}(\mathrm{HS}-\mathrm{co}-\mathrm{S})$.

\section{REFERENCES}

1. P. Dreyfuss and J. P. Kennedy, J. Polym. Sci., Polym. Symp., 60, 47 (1977)

2. A. Dondos, P. Lutz, L. Reibel, P. Rempp, and E. Franta, Makromol. Chem., 179, 2549 (1978).

3. T. Saegusa and S. Matsumoto, J. Polym. Sci., A-1, 6, 1559 (1968).

4. M. Takaki, R. Asami, and S. Tsuzuki, Polym. J., preceding paper in this issue.

5. H. Meerwein, Org. Synth., 46, 113 (1966).

6. M. Takaki, R. Asami, and M. Mizuno, Macromolecules, 10, 845 (1977).

7. T. Saegusa and S. Matsumoto, J. Macromol. Sci., A4, 873 (1970).

8. T. Fujimoto, M. Kawahashi, M. Nagasawa, and A. Takahashi, Polym. J., 11, 193 (1979).

9. E. Franta, F. Afshar-Taromi, and P. Rempp, Makromol. Chem., 177, 2191 (1976).

10. T. Kato, A. Itsubo, Y. Yamamoto, T. Fujimoto, and M. Nagasawa, Polym. J., 7, 123 (1975). 